\title{
QUI AUDIT ME: EL IDEAL DE POBREZA EN EL PENSAMIENTO DEL MAESTRO ECKHART \\ Guillermo Mañón*
}

\section{Introducción}

\section{$P_{\text {arece evidente para cualquiera que }}$} aspire a una sociedad justa que el problema de la recta distribución de la riqueza es de principal importancia. Desde los albores de la reflexión política ${ }^{1}$ se ha planteado el problema de la propiedad (común o privada) junto con el de la justicia social. Lo que quiere decir que el ideal de justicia va de la mano de la distribución equitativa de la riqueza.

La Alta Edad Media también lo entendió así y prueba de ello fueron los movimientos populares religiosos que enarbolaron el ideal de pobreza como forma fundamental de justicia. La reacción en contra de ellos no se

*Departamento Académico de Estudios Generales, ITAM.

${ }^{1}$ Por ejemplo, Pl., $R$., libros IV y VIII. hizo esperar por parte de la Iglesia, pues parece que no puede existir un poder sin concentración de riqueza.

En nuestros días resuena aún el eco de esa demanda de justicia, y como en aquel entonces, la Iglesia no ha hecho esperar su respuesta en contra de la teología de la liberación que ha visto en la realización del ideal evangélico de pobreza la conquista de justicia social, como muestra el documento eclesial de la Congregación para la Doctrina de la Fe, Libertatis Nuntius: ${ }^{2}$

Esta concepción totalizante impone su lógica y arrastra las 'teologías de la liberación' a aceptar un conjunto de posiciones incompatibles con la visión cristiana del hombre.

${ }^{2}$ http://130.94.75.135/documento.php?f doc $=2333 \& f$ tipo_doc $=9$ 
A esto respondió uno de sus representantes más conspicuos, Jon Sobrino, quien afirmó en entrevista hecha por el diario español El Mundo que el Vaticano se niega a entender el movimiento de la teología de la liberación, porque ésta pone en el centro de la discusión la adecuada repartición de la riqueza como condición sine qua non de la justicia social cristiana.

El Vaticano y la Teología de la Liberación han estado en relación veinticinco años. En mi opinión el Vaticano no ha entendido bien la Teología de la Liberación y probablemente no quiso entender y quizás no pudo entender, porque no es lo mismo estar allí (i. e. Roma) que estar aquí (El Salvador). ${ }^{3}$

El presente artículo quiere mostrar los preliminares medievales del presente debate que presenció la Alta Edad Media en torno al problema de la justicia y la pobreza. ${ }^{4}$

${ }^{3}$ Jon Sobrino, entrevista de Pascual Serrano para el periódico El Mundo de España, aparecida el 28 de Septiembre de 1994.

${ }^{4}$ No es mi intención presentar toda la doctrina social de la Iglesia católica, sólo referirme a la disputa en torno al ideal de pobreza evangélico entre los teólogos de la liberación y la congregación para la doctrina de la fe.

\section{Los movimientos religiosos laicos de pobreza de la Alta Edad Media}

A lo largo del siglo XII proliferaron muchos grupos laicos que predicaban con gran éxito en todas las esferas de la sociedad la renuncia a todo tipo de riqueza, se autoerigían en los auténticos seguidores de los apóstoles y del mensaje cristiano, y debido a su actitud anticlerical, se aproximaban a la herejía. ${ }^{5}$ Este fue conocido como el movimiento de pobreza, ${ }^{6}$ que el Papa Lucio III, por medio del decreto Ad abolendam, condenó en el año 1184 sin hacer distinción alguna entre Humiliati, Cátaros o Valdenses. ${ }^{7}$

De estos grupos, el más radical en su crítica contra la Iglesia fue el de los cátaros, que fustigó enérgicamente el lujo del clero regular y acusó a la Iglesia de Roma de ser

${ }^{5}$ H. Grundmann, Religiöse Bewegungen im Mittelalter, 1970, Darmstadt, WBG, p. 21.

${ }^{6}$ Algunos autores han propuesto que los movimientos de pobreza fueron también el resultado de la fe en el milenarismo o creencia en la segunda venida de Jesús, porque ésta aboliría la propiedad, el dinero, el clero, los reyes, los ricos y los pobres, las guerras, las naciones, etc. Una consecuencia del milenarismo era considerar que no se necesitaban ni los ritos ni los diezmos, porque éstos sólo servían para mantener a la clase corrupta del clero. Aquí se dejará de lado esta interpretación. V. Bauer, W., Rechtgläubigkeit und Ketzerei im ältesten Christentum, 1964, Tübingen, J.C.B. Mohr.

${ }^{7}$ J. D. Mansi, Sacrorum conciliorum nova et amplissima collectio, 1993, Düsseldorf, Patmos. 
una obra del demonio. ${ }^{8}$ La Iglesia reaccionó fuertemente contra esas críticas persiguiendo no sólo a los cátaros sino a todo grupo laico que tuviera cualquier relación o parecido con la herejía albigense. ${ }^{9}$

La mística alemana no se hurtó a la preocupación de los tiempos, antes bien sucumbió a la influencia de los movimientos populares de pobreza proponiendo la renuncia total, incluso la de uno mismo, como condición sine qua non para la unidad con Dios. Esto atizó aún más la confrontación entre la curia y los movimientos populares al grado que se hizo necesaria la fundación de órdenes religiosas dedicadas al combate contra estos movimientos de pobreza.

\section{Las órdenes mendicantes: dominicos y franciscanos}

Al comienzo del siglo XIII, y dentro de la influencia del movimiento de pobreza, surgieron las órdenes de franciscanos y dominicos. ${ }^{10} \mathrm{La}$ doctrina de Francisco de Asís - como anteriormente la de Pedro Valdo-se

${ }^{8}$ A. Borst, Die Katarer, 1953, Stuttgart, W. Kohlhammer, p. 231 s.

9 'Albigenses' por la ciudad de Albi en Languedoc, Francia, uno de los centros más importantes del movimiento cátaro.

${ }^{10}$ H. Grundmann, op. cit., p. 127 s. caracterizaba por una actitud crítica ante la Iglesia. En consonancia con los movimientos de pobreza de la época, enseñaba San Francisco la renuncia a la propiedad de los bienes materiales y la vida en pobreza como recta imitatio Cristi. ${ }^{11}$ La hermandad fundada por San Francisco fue vista en sus inicios con desconfianza por la Iglesia, incluso como una ramificación de los valdenses, porque los hermanos franciscanos no sólo rechazaban la propiedad individual sino también la colectiva, propia de toda orden. 'Inexplicablemente' la hermandad de Francisco de Asís obtuvo la aprobación papal por parte de Inocencio III y fue transformada en una orden religiosa pese a que su fundador no lo deseó nunca. ${ }^{12}$

La orden de los dominicos, que no estaba especialmente embebida por el ideal de la pobreza, se concentró desde el principio en el combate de las herejías predicando al pueblo en las plazas públicas para contrarrestar el efecto de los valdenses. Aunque los dominicos no hicieron de la pobreza la meta de sus ideales, sin embargo, al final de su vida Domingo

${ }^{11}$ K. Esser, Das Testament des Heiligen Franziskus von Assisi, 1949, Münster/Westfallen, p. 101.

${ }^{12}$ Sobre la orden de los franciscanos, v. J. N. Rasmussen, "Die Franziskaner in den nordischen Ländern im Mittelalter”, en Franziskanische Forschungen, 2002, Butzon \& Bercker, p. 600 s. 
de Guzmán, el fundador de la orden, enseñó la renuncia voluntaria a toda propiedad. ${ }^{13}$

Los dominicos asistían a las universidades argumentando que siempre y cuando dispusieran de una profunda preparación filosófica y teológica les sería posible realizar su tarea apostólica de atacar la herejía. ${ }^{14}$ Los franciscanos, incitados por la enorme rivalidad que existía en ese tiempo entre las dos órdenes mendicantes (ya se tratara de asuntos políticos o teológicos), exigieron también el derecho a la instrucción universitaria. Como esos estudios debían ser financiados de alguna forma, se hallaron los hermanos franciscanos obligados a hacer uso de la riqueza y propiedades de la Iglesia. Pese a eso, no creían transgredir los principios fundamentales de la orden, ya que quien aparecía como propietario de sus bienes era la curia apostólica, la Iglesia y no la orden franciscana. ${ }^{15}$

Este arreglo no satisfizo a todos los miembros de la orden franciscana que amenazaron con separarse de

${ }^{13}$ Sobre la orden de los dominicos, v. W.A. Hinnebusch, "Kleine Geschichte des Dominikanerordens", en Dominikanische Quellen und Zeugnisse, 2004, St. Benno, p. 200 s.

${ }^{14}$ Es evidente que identificar una herejía y elegir una estrategia de ataque exigía estudio y conocimiento sobre la doctrina eclesiástica.

${ }^{15}$ H. Grundmann, Neue Forschungen über Joachim v. Fiore, 1950, Marburg, Vandenhoeck \& Ruprecht. la comunidad y fundar otra que observara estrictamente los principios fundacionales de San Francisco. Uno de ellos, Gerardo von Borgo San Donino, veía en esta comunidad la realización de las profecías del monje de calabria, Joaquín de Fiore, que al final del siglo XII predicó la venida inminente de la era del Espíritu Santo y la disolución de la jerarquía eclesiástica. ${ }^{16}$

Cuando fue nombrado Buenaventura general de la orden de los franciscanos (1257), intentó conciliar a los cismáticos de su orden con una nueva interpretación de las reglas dictadas por su fundador. Pero las reglas de la hermandad, reiteradas por Francisco de Asís en el año 1226, exigían expresamente la renuncia a la propiedad y a sus derechos de usufructo. ${ }^{17}$ Buenaventura no reparó en moderar las reglas de su fundador para adaptarlas al escenario de los tiempos, reemplazando la renuncia total a la riqueza y propiedad por el usus moderatus y reinterpretando el ideal de pobreza franciscanos como humildad o pobreza de espíritu. Por esta razón, el grupo de radicales, fiel al espíritu original de su fundador, no declinó su postura y la

${ }^{16}$ H. Denifle, "Das Evangelium aeternum und die Commision zu Anagni", en Archiv für Literatur-und Kirchengeschichte des Mittelalters, 1978, Göttingen, Vandenhoeck \& Ruprecht, $\mathrm{n}^{\circ} 1$, p. $49 \mathrm{~s}$.

${ }^{17}$ K. Esser, op. cit., p. $101 \mathrm{~s}$. 
NOTAS

disputa sobre la propiedad alcanzó su punto más álgido con el cisma dentro de la orden entre el grupo de los conventuales, que reconocieron las modificaciones a las reglas de San Francisco, y el grupo de los espirituales, que permanecían fieles a las reglas primigenias. ${ }^{18}$

En relación a la postura de Buenaventura frente a la riqueza y propiedad dice Knowles: ${ }^{19}$

San Buenaventura no quedó libre de culpa en la controversia a la que sucumbió toda la Iglesia de occidente después de su muerte y 50 años en adelante. [...] La pauta para interpretar las reglas de San Francisco fueron las declaraciones y dispensas papales antes que el testamento de su fundador [...] consecuentemente, puso el énfasis en la pobreza de espíritu y recomendó una disposición frugal de los bienes materiales.

Buenaventura llamó a los espirituales a la obediencia, pero como él mismo no frenó el proceso de moderación de las reglas, no pudo impedir la escisión de la orden. Además, el uso moderado de los bienes materiales no se manifestó como

${ }^{18}$ Sobre la historia del movimiento espiritual v. K. Baltasar, Historia de la controversia sobre la pobreza hasta el concilio de Vienne, 1911, Münster, Piper, p. 28 s.

${ }^{19}$ D. Knowles, op. cit., p. 315. medida de comportamiento entre los conventuales, lo que fomentó el descontento de los espirituales. ${ }^{20}$

Estas confrontaciones que siguieron a la modificación de las reglas trascendieron a los franciscanos y polarizaron las pugnas eclesiásticas en el siglo XIII y XIV, al punto de que un inquisidor se negó a condenar por herejía a un espiritual que había afirmado la renuncia completa de Cristo a toda propiedad. ${ }^{21}$ En la Bula Exiit qui seminat del año 1279, el Papa Nicolás III apoyó la renuncia a la propiedad y bienes materiales con el fin de conciliar las partes y acordar que en el futuro el Papa detentaría tanto el derecho de propiedad como el derecho de usufructo de la orden franciscana. Sin embargo, esto tampoco resolvió el problema, porque de inmediato se vio que era improcedente y que la orden debía permanecer en disposición completa de sus bienes y ganancias. Los ataques de los espirituales contra el Papa no se hicieron esperar así como tampoco la reacción de la curia contra los espirituales: en el año de 1322 el Papa Juan XXII pretendió resolver definitivamente el problema al declarar en la bula Quia nonnumquam que Cristo, como cabeza de la Iglesia, y sus apóstoles

\footnotetext{
${ }^{20}$ K. Baltasar, op. cit., p. 29.

${ }^{21}$ D. Knowles, op. cit., p. 319.
} 
poseyeron propiedades aún cuando podrían haber renunciado a ellas, y les confirió a los franciscanos, con la bula Ad conditorem canonum, el completo derecho a posesión de propiedad privada.

El movimiento de los espirituales rápidamente adquirió una dimensión política poniendo en entredicho las ambiciones papales a riqueza y propiedad y espoleando las confrontaciones entre reyes y papas. El rey Luis de Baviera, por ejemplo, aprovechó la controversia para acusar al Papa Juan XXII de hereje y protegerse frente a la feligresía de cualquier ataque de excomunión por parte del Papa. ${ }^{22}$ En esta reyerta, entre Luis de Baviera y la curia de Avignon, jugaron los franciscanos un papel muy significativo. Nadie más, salvo Guillermo de Ockham se puso de parte de la separación entre Iglesia y Estado ${ }^{23}$ y postuló la realización de la pobreza cristiana en

${ }^{22}$ J. Schwalm, Die Sachsenhausener Appellation Kaiser Ludwig des Bayern von 22 Mai 1324 , t. v, n 909 , p. 722.

${ }^{23}$ Marsilio de Papua (1290-1342) enunció de manera más sistemática que Ockham la teoría aristotélico averroísta de la separación del poder civil y religioso. Sabine afirma lo siguiente sobre Marsilio de Papua: "La teoría política de Marsilio de Papua es una de las más notables creaciones del pensamiento político medieval y mostró por primera vez las consecuencias subversivas a que podía llevar lógicamente una interpretación completamente naturalista de Aristóteles", G. Sabine, Historia de la teoría política, 1994, México, FCE, p. 233-51. toda la Iglesia. Antes de su condena en Avignon, escapó y se refugió en Baviera recibiendo asilo del rey. ${ }^{24}$

Los dominicos, con excepción de algunos, permanecieron fieles al Papa y en relación a la pobreza nunca se desviaron de las disposiciones papales. El mismo Eckhart muestra el comportamiento típico de la orden dominica en su conjunto respecto al problema de la pobreza. Los dominicos predicaron el uso moderado de los bienes materiales y la pobreza de espíritu, y nunca interpretaron el voto de pobreza como renuncia total a los bienes materiales y a todo tipo de propiedad.

\section{Evolución del ideal de pobreza dentro de las órdenes mendicantes}

Con el correr de los años y como consecuencia de la rivalidad entre ellas, ambas órdenes se desentendieron del ideal de pobreza, ambicionando los puestos importantes en la curia y las plazas de enseñanza en las universidades. Sus teólogos se encargaron de la dispensa por medio de una adecuada interpretación de la pobreza y recta actitud frente a la posesión de bienes materiales. De esta manera, aclaraba Tomás de Aquino,

${ }^{24}$ E. Iserloh, op. cit., p. 448 s. 
apoyándose en la Biblia ${ }^{25}$ y en Aristóteles, ${ }^{26}$ que la posesión de riqueza es compatible con el ser cristiano. ${ }^{27}$ Esta tesis valía no sólo como norma de comportamiento de la orden dominica, sino también como visión fundamental de la doctrina cristiana después de la declaración de santidad de Tomás de Aquino en el año 1325. Eckhart también se sumó al esfuerzo de solucionar el conflicto con su interpretación de la pobreza y recto comportamiento frente a la riqueza; en lugar de pensar en la pobreza como renuncia a bienes materiales, concibió la pobreza como un rasgo espiritual.

Por parte de los franciscanos, éstos se concibieron, por lo menos en sus comienzos, como un movimiento reformador que intentó llevar a la práctica los ideales evangélicos de pobreza total. Pero con el fin de asegurar su existencia, renunciaron a ese ideal de pobreza poco después

${ }^{25}$ Por un lado en el Evangelio según San Mateo, 6-7, se lee: "Nadie puede servir a dos señores, pues o bien, aborreciendo a uno, amará al otro, o bien, adhiriéndose al uno, menospreciará al otro. No podéis servir a Dios y a las riquezas." Por otro San Pablo, "poseer las cosas como si no las poseyéramos".

${ }^{26}$ Aristóteles, EN, I, VII (1097b). Santo Tomás, Sobre el Reino, XV: "Sin bienes materiales es imposible que un hombre sea feliz o virtuoso."

${ }^{27}$ En contraposición a la teología franciscana sostuvo Tomás de Aquino que la propiedad privada no era una consecuencia del pecado. Cfr. Summa Theologica, II, II, q. 66, art. 2. de su fundación. Mientras que dentro de los franciscanos esta nueva orientación llevó a la escisión de la orden, a los dominicos no les costó trabajo dar este paso, ya que ellos se dedicaron primordialmente a la conversión de herejes.

Tarde o temprano, ambas órdenes abandonaron el cumplimiento estricto del ideal de pobreza y adoptaron una actitud más moderada frente a la riqueza, calificando la recta pobreza como 'pobreza de espíritu', no obstante que fue la actitud opuesta la que les dio gran difusión y prosélitos en toda Europa.

El éxito de los dominicos y franciscanos a lo largo del siglo XIII se explica ante todo porque, en contraposición de los monjes benedictinos, se adaptaron a las necesidades de los tiempos con el fin de impedir la pululación de los herejes. En el comienzo, ambas órdenes abandonaron los privilegios propios de los prelados eclesiásticos y vivieron de la modesta remuneración de sus trabajos artesanales. Con ese espíritu religioso ante la riqueza y propiedad, podían las órdenes mendicantes hacer frente a las críticas acérrimas de los movimientos populares de pobreza que reparaban ante todo en la opulencia de la Iglesia. Los herejes no podían acusar a los mendicantes de ningún exceso, por eso puede decirse que con los franciscanos y dominicos 
recibían los papas "un nuevo tipo de milicia a su disposición, que podían utilizar del modo como antes nunca fue posible con los altos prelados y el clero regular". ${ }^{28}$ Además, los dominicos no sólo se daban por satisfechos con la conversión de los herejes sino que los acogían en sus conventos como miembros de su orden.

\section{Eckhart y los movimientos populares de pobreza}

Cuando Eckhart y Taulero comenzaron a predicar el ideal evangélico de la pobreza de Cristo, no era nueva ni la preocupación por la recta actitud ante la riqueza ni la literatura alemana que abordaba estos temas; antes bien los precedían siglos de historia eclesiástica empeñada por cumplir el mensaje evangélico, como aquella promovida tenazmente en los albores de la Alta Edad Media por Gregorio VII ${ }^{29}$ con el fin de rectificar los traspiés del movimiento monacal. ${ }^{30}$ De la misma manera, los antecedentes literarios de la mística alemana se encuentran en los siglos

${ }^{28}$ M. Knowles, "Die Mendikanten, Ürsprunge und Ausbreitung", en Geschichte der Kirche, t. 2, Hrsg. L. J. Rogier, R. Aubert, M. D. Knowles, 1971, Einsideln, Zürich, Köln, p. 312.

${ }^{29}$ Papa de 1073 a 1085.

${ }^{30} \mathrm{H}$. Holze, Kirche und Mönchtum im 12. und 13. Jahrhundert, 2003, Berlín, Evangelische Verlagsansta, p. 200-50.
XI y XII, en los grandes poetas del período de los Staufer, como por ejemplo Walther von der Vogelweide (1170-1230), ${ }^{31}$ que si bien enfrentó el problema de la recta actitud frente a al riqueza, no acertó a dar una respuesta satisfactoria con su declaración de inconformidad frente a las inclinaciones de sus contemporáneos, aunque tampoco propuso la desavenencia con el mundo.

En el siglo XIII la preocupación de estos dominicos residía en prevenir a la feligresía de los errores en la interpretación de la imitatio Cristi respecto a la renuncia a la propiedad y riqueza ${ }^{32}$ y en llevar de vuelta a los rediles de la Iglesia y ortodoxia a los numerosos grupos de laicos que se hubiese extraviado en su deseo de reforma eclesiástica. La ética del maestro Eckhart, por ejemplo, gira en torno al ideal de la pobreza de espíritu y tiene como punto de partida la recta actitud del hombre frente a los bienes terrenales. Partiendo de la 'pobreza de espíritu' como postulado evangélico, Eckhart se afana

31 También habría que citar a los poetas Hartmann von Aue (1160-1210) y Wolfram von Eschenbach (1171-1220), V. Th. Bein, Walther von der Vogelweide, 1997, Leipzig, Reclam, p. $102-20$.

${ }^{32}$ Grundmann, Religiöse Bewegungen im Mittelalter, 1970, Darmstadt, WBG. Ahí mismo se encuentra "Neue Beiträge zur Geschichte der religiöse Bewegungen im Mittelalter", II. Deutsche Mystik, Beginentum und Ketzerei des 'Freie Geistes', p. 524. 
en explicar el recto desprendimiento de toda propiedad y riqueza a este público de religiosos laicos. Los más populares en Alemania fueron los hermanos del espíritu libre, las beguinas y los begardos, que al igual que los valdenses intentaron ofrecer una respuesta por medio de una vida en estricta pobreza, que a la vez fungió como una crítica enérgica contra el boato de los clérigos.

En Alemania, las comunidades laicas de mujeres (beguinas) se multiplicaron siguiendo la tradición monástica $^{33}$ y encontraron en los mendicantes una enorme acogida. Esas comunidades femeninas -se les nombraba beguinas ${ }^{-34}$ cayeron bajo sospecha de herejía debido a la práctica de una estricta pobreza y renuncia a todo tipo de propiedad y riqueza. Para protegerse de la persecución inquisitorial, buscaron la

${ }^{33}$ H. Holze, op. cit., p. 138 s.

${ }^{34} \mathrm{La}$ aclaración sobre el término 'Beguina' es la siguiente, según Unger: "La etimología de los nombres Begardo y Beguina solamente pueden ser conjeturados. Probablemente hayan derivado de la palabra beghen en flamenco antiguo, con el sentido de 'pedir' ('rezar'). Tal vez deriven de la palabra Bega, santo patrón de Nivelles, en donde, según una dudosa tradición, el primer Beguinage fue establecido. Tal vez, de nuevo, derive de Lambert le Bègue, sacerdote de Liège quien murió en 1180, después de haber gastado una fortuna en la fundación de una iglesia y claustro para viudas y huérfanos de los cruzados en su pueblo nativo", H. Unger, Die Beginen Geschichte von Aufbruch und Unterdrückung der Fraüen, 2005, Herder Verlag, Spektrum Taschenbücher, p. $155 \mathrm{~s}$. filiación a una orden reconocida. ${ }^{35} \mathrm{El}$ Papa comisionó a los dominicos con el cura monialium a dar asistencia espiritual a los conventos de monjas beguinas. ${ }^{36}$ Grundmann nos informa que al final del siglo XIII se habían incorporado más de 80 conventos de mujeres a la orden de los dominicos en espera de dirección espiritual. ${ }^{37}$

Partiendo de este contexto se entiende por qué el tema de la pobreza juega un papel central en el pensamiento de Eckhart al tener que predicar frente a grupos de beguinas.

Grundmann ${ }^{38}$ repara en lo siguiente al reflexionar sobre los orígenes de la mística alemana:

Su relación (de las beguinas) con la teología dominica a través de la asistencia espiritual y su propia espiritualidad femenina, crearon las condiciones para el surgimiento de la mística alemana.

Grundmann parece tener razón porque el movimiento religioso de mujeres laicas (i. e. beguinas) ya se había constituido antes que llegaran las órdenes mendicantes a Alemania, y ciertamente tenía sus raíces en p. 531.

${ }^{35}$ H. Grundmann, Religiöse Bewegungen,

${ }^{36}$ Ibidem, p. 284.

${ }^{37} \mathrm{H}$. Grundmann, Deutsche Vierteljahrschrift für Literaturwissenschaft und Geschichte, 1934, Göttingen, Vandenhoeck \& Ruprecht, t. 12, p. 414.

${ }^{38}$ H. Grundmann, op. cit., p. 527. 
los movimientos de pobreza de los siglos XII y XIII; no obstante puede afirmarse que el movimiento místico alemán tuvo su cenit gracias a los sermones de Eckhart. Sin embargo, la intención primordial de Eckhart era mitigar con su ética religiosa las tensiones que existían entre la curia de Avignon y los grupos de las beguinas. ${ }^{39}$

A diferencia de los movimientos de pobreza del siglo XIII, consideraban los místicos alemanes la propiedad como algo no reprobable en sí mismo sino como algo que dependía de la actitud interna del hombre. Correspondiendo a esto, Taulero y Eckhart consideraban que alguien podía ser rico y gozar de reconocimiento y, no obstante, permanecer pobre en espíritu. ${ }^{40} \mathrm{La}$ actitud 'interna' frente a la pobreza o riqueza era para ellos más importante que la actitud 'externa'. La doctrina de Eckhart frente a la pobreza puede entenderse en parte como crítica a las posturas radicales de los movimientos laicos de pobreza. ${ }^{41}$ Para Eckhart, el hombre debe deshacerse de las ataduras internas a los bienes

${ }^{39}$ G. Hoffmann, "Die Brüder und Schwestern des freien Geistes zur Zeit Heinrich Seuses", en Studien zum 600, 1966, Köln, Todestag H. Seuses Hrs. von E. Filthaut, p. 352.

${ }^{40}$ Eckhart, DW (obra alemana), Stuttgart, W. Kohlhammert (ed. J. Quint), t. 2, p. 147.

${ }^{41}$ H. Kunisch, "Offenbarung und Gehorsam”, Eckhart-Festschrift, p. 134. mundanos y dejar de contemplarlos como la realización de su Yo. ${ }^{42}$ Esta es para Eckhart la actitud de un buen cristiano y no la renuncia 'exterior' a la propiedad.

En coincidencia con los movimientos no ortodoxos de su tiempo, sostenía Eckhart la profunda convicción de que la práctica de una ética religiosa realizaría el ideal cristiano de pobreza espiritual. También con los herejes de su tiempo compartió Eckhart el mismo destino, porque en 1326 se abrió un proceso inquisitorial en contra suya, ordenado por el arzobispo de Colonia Heinrich von Virneburg. ${ }^{43}$ En el año 1329 con la bula In agro dominico, el Papa Juan XXII condenó varios de los escritos de Eckhart por heréticos. Eckhart se defendió de las acusaciones, pero como buen representante de la orden de los dominicos no se sublevó contra las autoridades eclesiásticas. Eckhart se limitó en principio a objetar la autoridad del arzobispo de Colonia de

${ }^{42}$ Ésta es también la postura de sus discípulos. Cfr. Meister Eckhart und seine Jünger. Ungedruckte Texte zur Geschichte der deutschen Mystik, 1895, Freiburg (Schweiz), Hrsg. F. Jostes, p. 29.

${ }^{43}$ El arzobispo de Virneburg perseguía en esa época a los hermanos y hermanas del espíritu libre. El pretexto para la denuncia de Eckhart fue la declaración de admiración por Eckhart de los hermanos y hermanas y de que lo consideraran uno de los 'suyos', I. Degenhart, Studien zum Wandel des Eckhartsbildes, 1986, Stuttgart, J. B. Metzler, p. 30. 
NOTAS

llamarlo a rendir cuentas a él, maestro dominico de teología, y exigió la intervención del Papa.

Antes de su muerte, Eckhart se desdijo de los escritos o sentencias 'sospechosos' de herejía. Pero es de notar que en su doctrina sobre la pobreza-como antes lo había hecho Buenaventura- la pobreza 'interna', de espíritu, lleva la primacía, y frente a la propiedad recomienda el uso frugal o moderado de los bienes terrenales. ${ }^{44}$ De igual forma, en la mística alemana, a que dieron lugar sus sermones, aparece la pobreza de espíritu y el uso moderado de los bienes materiales como insigne virtud del hombre. ${ }^{45} \mathrm{Y}$ a manera de apostilla, hay que agregar que ésta no fue una postura 'precautoria' al final de sus años, porque Eckhart fue fiel toda su vida a la actitud moderada como delatan sus interpretaciones tempranas de la doctrina evangélica sobre la pobreza. ${ }^{46} \mathrm{Ni}$ Eckhart ni Taulero se manifestaron alguna vez

${ }^{44}$ Buenaventura interpretó la pobreza de espíritu como la renuncia a dominio y propiedad. El uso restringido de los bienes terrestres no significa para él ninguna violación del mandamiento evangélico de pobreza. Cfr. M. D. Lambert, Franciscan poverty. The doctrine of absolute poverty of Christ and the apostols in the franciscan Order 1210-1323, 1961, London, Routledge \& Kegan Paul, p. 127 s.

${ }^{45}$ Paradisus anima e intelligentis, 1919, Berlin, hrsg. von Ph. Strauch, Deutsche Texte des Mittelalters, t. 30, p. 70 s.

${ }^{46}$ Eckhart, Rede der Unterweisung, DW, t. V, p. 300,1 . contra la posesión de bienes materiales, como sí fue el caso de los espirituales franciscanos. Por eso, puede rechazarse su influencia en el pensamiento del maestro dominico como razón de su condena o la simpatía con cualquier otro grupo herético cualquiera.

¿Cómo explicarse el proceso inquisitorial y condena en su contra cuando la doctrina sobre la pobreza de Eckhart es harto abstracta y filosófica, compenetrada de neoplatonismo? La 'desmaterialización' de la paupertas en el pensamiento de Eckhart debió de haber gozado del beneplácito de la orden dominica y de la curia en general. Algunos han insinuado que la rivalidad entre las órdenes mendicantes llegó al punto de eliminarse mutuamente denunciándose ante la inquisición. A favor de esta interpretación habla el hecho de que Miguel de Cesena y el mismo Guillermo de Ockham, que simpatizaban con los espirituales, colaboraron con la condena del Maestro Eckhart. ${ }^{47}$ Ambos informan que Eckhart era responsable de la diseminación de la herejía en Alemania. ${ }^{48}$ También fueron franciscanos

${ }^{47}$ Cfr. J. Koch, "Einführung”, en Festschrift, 1960, Freiburg-Basel-Wien, Hrsg. U. Nix y R. Öchslin, p. 17.

${ }^{48}$ J. Koch, "Meister Eckhart Weiterwirken", en La Mystique rhénane, 1963, París, Hachette, p. 133. 
los testigos de cargo en el proceso contra Eckhart. ${ }^{49} \mathrm{Si}$ a esto se suma el hecho de que Eckhart era una de las grandes personalidades entre los dominicos y la cristiandad occidental, puede entenderse que su actividad con las beguinas estaba provocando un movimiento religioso que palidecía a sus rivales de orden.

Eckhart nunca cuestionó el derecho de la Iglesia a riqueza y propiedad y nunca tomó partido contra el Papa (llamado por sus enemigos el rey Midas). Es más, como Buenaventura, observaba Eckhart la humildad (dêmuot) como indicio de verdadera pobreza de espíritu, ${ }^{50}$ y siempre advirtió a sus discípulos de ser cuidadosos en la interpretación de la pobreza material. La pobreza material no es ninguna virtud, y por eso no lleva a la perfección..$^{51}$ En su opinión, la virtud no reside en la renuncia 'externa' de bienes materiales, sino sólo en devenir 'interiormente' libre de toda dependencia de lo mundano. ${ }^{52} \mathrm{La}$ virtud de la renuncia (Gelassenheit, Abgeschiedenheit) que se realiza en la separación interior o espiritual de toda inclinación e interés por lo terrenal es lo que significa pobreza de espíritu.

\footnotetext{
${ }^{49}$ Ibid., p. 110.

${ }^{50}$ Eckhart, DW, t. II, p. 450, 4.

${ }^{51}$ Ibid., t. V, p. 193.

52 Ibid., p. 194.
}

Eckhart tiende más al pensamiento y postura de un Buenaventura que de un Francisco de Asís, el cual por cierto poco aprecio sentía por las especulaciones filosóficas. La doctrina de Eckhart sobre la paupertas spiritu es mucho muy abstracta y mucho muy impregnada de los conocimientos de los maestros de París como para compararse a la práctica de la pobreza de bienes y de espíritu de San Francisco. La personalidad de Eckhart, su carrera como maestro de teología y su actividad predicadora ${ }^{53}$ no se adecuaban al ideal que tenía San Francisco sobre la humildad.

H. Grundmann ${ }^{54}$ dice con razón cuando pone la raíz de la mística alemana en relación con los movimientos de pobreza del siglo XII y XIII. Pero no hay que olvidar que tanto Eckhart como sus discípulos Susón y Taulero estaban empeñados

${ }^{53}$ Sobre la vida del Maestro Eckhart v. J. Koch, "Kritischen Studien zum Leben Meister Eckharts", en Archivum Fratrum Praedicatorum, 1959, Berlin, Akademie-Verlag, n² 29, p. 5-51.

${ }^{54} \mathrm{Si}$ bien Grundmann en su libro Religiöse Bewegungen im Mittelalter explica el surgimiento de la mística alemana como un fenómeno 'paralelo' a los movimientos laicos y franciscano de pobreza de los países latinos, no debe de enfatizarse tanto la etiqueta 'mística alemana' como 'religiosidad dominica', porque tanto Eckhart como Taulero deseaban una mística fiel a la catolicidad, al clero y ambos representarían la reacción a la postura franciscana de la pobreza extrema. Ciertamente, la acusación de hereje contra Eckhart aparece como un mentís frente a esta tesis, por eso sería necesario en otra ocasión analizar también el proceso inquisitorial contra Eckhart en su contexto. 
en predicar un ideal de la pobreza que rectificara la mala interpretación acogida por los movimientos heréticos. ${ }^{55}$ El ideal de pobreza pierde en Eckhart su aspecto 'exterior', su fuerza crítica contra la opulencia del clero, y cobra una dimensión teórica, teológica, que la diferencian radicalmente de la postura hereje de los movimientos religiosos laicos sobre la propiedad y la pobreza.

La siguiente traducción del sermón alemán $n^{\circ} 12$ define el ideal místico de la pobreza de espíritu como lo predicó Eckhart innumerables veces frente a las beguinas. La influencia del movimiento de pobreza en el origen o surgimiento de la mística alemana es innegable, pero las consideraciones éticas que se desprenden de esa mística se diferencian radicalmente de la postura hereje sobre la propiedad.

Sermón 12: Qui audit Me (Eccli. $24,30)^{56}$

Esta palabra que he pronunciado en latín, la pronuncia la sabiduría eterna

55 Eckhart desconfió de la obsesión de la pobreza de bienes materiales que no convertían al hombre en pobre de espíritu. A la entronización de la pobreza 'exterior' (i. e. de bienes materiales) reaccionó Eckhart con escepticismo. Cfr. Eckhart, $D W$, t. V, p. 193,5 .

${ }^{56}$ La traducción de la edición crítica de los sermones alemanes $(D W)$ editados por J. Quint es mía. del Padre, y dice: "Aquel que me escucha, no se avergonzará" - cuando alguien se avergüenza de cualquier cosa, entonces se avergüenza de avergonzarse- "aquel que actúa en mi nombre, no pecará. Aquel que me manifieste y me haga brillar, obtendrá la vida eterna" (Jes. Sir. 24, 30/31). De esas tres palabritas que he pronunciado, le sobra a cualquiera para dictar un sermón.

Primeramente, quiero hablar sobre lo que dice la sabiduría: "Aquel que me escucha, no se avergonzará". El que desee escuchar la sabiduría del Padre, debe permanecer dentro, en casa, y debe ser uno, entonces podrá escuchar la eterna sabiduría del Padre.

Tres cosas son las que nos impiden escuchar la palabra eterna. La primera es corporeidad, la segunda multiplicidad, la tercera temporalidad. Si el hombre hubiese prosperado más allá de estas tres, entonces habitaría en la eternidad, habitaría en el espíritu, habitaría en la unidad y en el desierto, y ahí escucharía la verdad eterna. Ahora habla Nuestro Señor: "nadie escucha mi palabra ni mis enseñanzas, más que aquel que se ha abandonado" (Lc 14, 26). Porque el que desee escuchar la palabra de Dios, debe haberse abandonado. Aquel que escucha, es el mismo que será escuchado en la palabra eterna. Todo lo que enseña el Padre es su ser 
y su naturaleza y su divinidad entera; Él nos los manifiesta ante todo en su Hijo y nos enseña que nosotros somos ese mismo Hijo unigénito. El hombre que partiera de ahí, y de esa manera, sería el unigénito Hijo; a ése le pertenecería exactamente lo que le pertenece al Hijo unigénito. Lo que Dios obra y lo que Él enseña, eso mismo obra y enseña a todos en su Hijo unigénito. Dios ejecuta toda su obra con el fin de que nosotros lleguemos a ser su Hijo unigénito. Cuando Dios mira que nosotros somos su Hijo unigénito, entonces nos apremia tan fuertemente y nos apresura y hace con nosotros exactamente como si su ser divino se destrozara y deseara en sí mismo llegar a destruirse con el fin de que Él nos manifieste el abismo completo de su divinidad y la plenitud de su ser y de su naturaleza. Dios tiene urgencia de que nos apropiemos de Él, de la misma forma como Él se pertenece a sí mismo. En esto reside la plenitud de gozo y deleite divino. Ese hombre se encuentra en el conocimiento de Dios y en el amor de Dios, y no será otra cosa que lo que es Dios mismo.

Si te tienes amor a ti mismo, entonces les tendrás amor a todos los hombres como a ti mismo. Mientras a un sólo hombre le tengas menos amor que a ti mismo, en esa medida habrás extraviado el amor verdadero por ti mismo, si no amas a todos los hombres como a ti mismo, a todos los hombres en un hombre, porque ese hombre es Dios y el hombre. El hombre que se ama a sí mismo y a todos los hombres como a él mismo, con ése está todo en orden, la razón le asiste a un hombre semejante.

Ahora bien; algunas personas dicen: "yo amo, con preferencia de otro cualquiera, al amigo del que recibo cosas buenas". Eso no está bien y es descaminado. Ciertamente, hay que conceder que para algunos no obsta contar con medio viento para hacerse a la mar y llegar a buen puerto. Y no ocurre otra cosa a la gente que ama más a un hombre que a los demás: es natural. Si le amara con el amor que me tengo a mí mismo, entonces todo lo que le ocurriera para bien o para mal, fuera la muerte o la vida, sería para mí igualmente querido, como si a mí me ocurriera al parejo que a él, y en esto consiste la verdadera amistad.

Por eso dice San Pablo: "quisiera eternamente estar separado de Dios por amor a mis amigos y a Dios" $(R m, 9,3)$. Un pestañeo separado de Dios significa estar eternamente separado de Dios; separado de Dios es pesar infernal. Entonces, ¿cuál es el sentido de las palabras de San Pablo cuando expresa su deseo de estar separado de Dios? Aquí se preguntan los maestros si San Pablo se hallaba en el camino de la perfección o si más bien se encontraba ya en la 
perfección. Yo opino que él se encontraba ya en la perfección, de otra manera no podría decir esto. Ahora bregaré para esclarecer esas palabras de San Pablo, a saber, desear estar separado de Dios.

Lo más elevado y extremo que el hombre puede abandonar es a Dios por amor a Dios. De esa manera abandona San Pablo a Dios por amor a Dios. Él abandona todo aquello que él puede tomar de Dios y abandona todo aquello que Dios le puede dar y todo aquello que puede él recibir de Dios. Cuando abandona todo esto, entonces abandona a Dios por amor a Dios y permanece Dios en él de la forma como Dios existe en sí mismo, no a la manera en que llega a ser recibido - o a la manera en que llega a ser ganado-, sino en su existencialidad (Seinsheit) que es Dios en sí mismo.

Él no le da a Dios nada, tampoco recibe nada de él; es una unidad y una pura unificación. Aquí es el hombre un verdadero hombre, y en ese hombre no tiene lugar sufrimiento alguno como tampoco puede caber sufrimiento alguno en el ser divino. He dicho frecuentemente que hay algo en el alma emparentado tan íntimamente con Dios que constituye unidad y no unificación. Es uno, no tiene con nada algo en común, tampoco es en él nada parecido a cosa creada cualquiera. Todo lo creado es pura nada, por eso esto es ajeno a todo lo creado. Si estuviera el hombre entero formado de esta manera, entonces sería completamente increado y sin posibilidad siquiera de ser creado. Si todo lo corporal y afectado de insuficiencia estuviera comprendido en la unidad de esta misma forma, entonces no habría otra cosa que la unidad. Si me hallara enteramente, aunque fuera sólo un abrir y cerrar de ojos, en ese ser, cuidaría de mí mismo tan poco como de un gusanillo estercolero.

Dios da a todas las cosas por igual, y por fluir todas ellas de Dios, por eso mismo son todas ellas iguales: sí; ángel y hombre y todas las criaturas fluyen de Dios como iguales en su primera emanación. Son iguales incluso en tiempo; de manera que en la eternidad de Dios son aún más iguales. Considera una mosca en Dios, y resulta más distinguida en Dios que cualquier ángel en sí mismo. Ahora bien; todas las cosas son en Dios iguales y son Dios mismo.

Aquí, en esta igualdad, el alborozo de Dios se dilata tanto que toda su naturaleza y su ser colman totalmente esa igualdad. Para Él eso es alegría inmensa al modo como quien deja correr un potrillo al filo de la pradera verde y llana. El potrillo, correspondiendo a su naturaleza, se derrama en la pradera brincando con todas sus 
fuerzas: corresponder con su naturaleza le depara alegría enorme. Pues, de la misma manera, depara alegría inmensa a Dios encontrar igualdad. Y es una alegría tal, que derrama en la igualdad su naturaleza y su ser, porque Él es la igualdad misma.

Ahora bien; uno se plantea la pregunta respecto a los ángeles: si cada ángel que aquí entre nosotros habita, nos sirve y protege, si tienen una igualdad y alborozo inferior a la de aquellos que están en la eternidad, o si ellos en virtud de la acción de protegernos y hacernos un servicio de manera alguna empequeñecen. Yo respondo: ¡no, de ninguna manera! $\mathrm{Su}$ alegría e igualdad es por lo mismo nada inferior, porque las acciones de los ángeles son la voluntad divina y la voluntad divina es la obra de los ángeles. Por eso, nada obstaculiza su alegría ni su igualdad ni tampoco en sus obras. Fuera el caso que Dios dijera al ángel mueve un árbol o retira las orugas de su follaje, el ángel estaría dispuesto a retirar las orugas y en eso radicaría su bienaventuranza y cumpliría la voluntad de Dios. El hombre que se encuentra de esa manera en la voluntad divina, no desea otra cosa que lo que Dios es y lo que la voluntad de Dios es. Si fuera el caso estar enfermo, no desearía estar sano. Todas las desgracias son para él alegría, toda multiplicidad es simplicidad y unidad cuanto más se encuentra en la voluntad de Dios. Si todo dependiera de una pena infernal, incluso ésa sería una alegría y bienaventuranza para él.

Él está libre y vaciado de sí mismo y de todo aquello que él reciba; de todo debe estar libre. Si ha de ver mi ojo los colores, entonces debe estar libre de todo color. Veo color azul o color blanco: la visión de mi ojo consiste en que el ojo perciba el color-exactamente eso, lo que ve, es lo mismo que aquello que es visto por el ojo. El ojo con el cual veo a Dios, es exactamente el mismo ojo con el que Dios me ve; mi ojo y el ojo de Dios es uno y el mismo ojo, y el mismo acto de mirar y el mismo acto de conocer y el mismo acto de amar.

El hombre que de esta manera se halla en el amor de Dios, debe estar muerto en sí mismo y en todas las cosas creadas, de tal forma que atienda a sí mismo como lo atiende aquel que está cientos de millas alejado de él. Un hombre semejante permanece en la igualdad y permanece en la unidad y permanece completamente igual; en él sucumbe toda desigualdad. Ese hombre debe haberse abandonado a sí mismo y haber abandonado el mundo. Hubiera un hombre a quien perteneciera el mundo, y ése abandona el mundo por amor de Dios, así desnudo como él lo hubiera recibido, a él le daría Nuestro Señor de vuelta todo ese mundo además de la vida 
eterna. Y si hubiera algún otro hombre que no poseyera otra cosa que una buena voluntad, y que pensara: Señor, fuera ese mundo mío y tuviera aún un mundo más y uno más -lo que sumaría tres- y anhelara: Señor, yo deseo abandonarlo, así como a mí mismo, enteramente, de la misma forma como yo lo he recibido de ti, ese hombre daría tanto a Dios como lo que él mismo con su propia mano hubiera desechado. Algún otro hombre que nada corporal o espiritual tuviera para abandonar, sería el que más abandonaría. Aquel que pudiera abandonarse completamente en un abrir y cerrar de ojos, a ése se le con- cedería todo. Si un hombre estuviera veinte años enteros abandonado, y se recuperara a sí mismo por sólo un abrir y cerrar de ojos, pues debido a eso no podría haberse abandonado nunca. El hombre que se ha abandonado, y permanece abandonado, $y$ nunca más, ni siquiera por un abrir y cerrar de ojos, repara en eso que él ha abandonado, permanece inamovible en él mismo y sin cambios -sólo así está ese hombre abandonado.

Que nosotros así nos conservemos permanentemente y sin modificación posible como el Padre eterno, para ello nos ayude Dios y la sabiduría eterna. Amén. 